when he implies that only the last two elements were really necessary.

Taylor's mathematics are touched on in places, for example his use of the timehonoured method of similarity solutions. His approach was to find a convenient and tractable mathematical solution and not to worry too much about when it might be valid, or whether it was unique or even properly existed; he regarded such questions as pedantic or, if they were important, believed that they could easily be resolved by recourse to physical argument or experiment. However, as Norbert Wiener pointed out, Taylor certainly did introduce new mathematical thinking in the study of random processes. Although we can still learn much from his approach, the extensive and deeper use of computing has forced applied mathematicians and physicists to become more mathematical in their analyses of problems in mechanics.

Does the book indicate how Taylor's achievements related to his personality, his upbringing and the institutions where he studied and worked? Batchelor gives his views but also enough material for the reader to piece together his or her own. Taylor had a creative north London background, the son of an illustrator and educated at the nonconformist, intellectually self-confident University College School. He sailed down to the mouth of the Thames in a home-made boat as a teenager. This upbringing certainly seems consistent with the photographs of the confident young man who answered back to the captain of the Scotia; who requested his fiancée in the 1920 s to read John Donne's poetry on the 'corporeal' aspects of love; who flew his own experimental plane in the First World War; and who in 1945, when in his $60 \mathrm{~s}$, was not afraid to publish his estimates of the strength of the Hiroshima atom bomb (to the distinct disapproval of the US authorities).

Batchelor emphasizes Taylor's lack of political and social opinions; but Taylor did have strongly held views about the world's rapidly growing population, a common view in his generation, and well known in circles connected with University College. Nevertheless, he was an enthusiast, at least, about some aspects of modern life, including, apparently, water-skiing at the age of 80 !

My only complaint on reaching the end of this most enjoyable book is that there are not more stories about Taylor or about the factors and friends that influenced him early in his career; I hope that the search for correspondence about him will continue. This is a splendid book and it needed to be written by Batchelor, Taylor's great admirer and interpreter.

J. C. R. Hunt is in the Department of Applied

Mathematics and Theoretical Physics,

University of Cambridge, Silver Street,

Cambridge CB3 9EW, UK.

\section{After the Ark}

Noah's Flood: The Genesis Story in
Western Thought
by Norman Cohn
Yale University Press: 1996. Pp. 150. \$30,
E19.95
Martin Rudwick

Whenever science and religion are mentioned together, the image of perennial conflict continues to predominate, not only with the public but also among scientists. Yet the 'conflict model' has long been abandoned by historians of science as a gross oversimplification of a complex and fluid relationship. Abandoning stereotypes brings rewards, in opening the way for a more realistic understanding of the public uses of scientific knowledge - and not only of uses framed in religious terms.

Among points of potential interaction, the Flood in Genesis has had a historically unique status. Almost alone among the events that crowd the biblical narratives, and that have been endowed with human significance by religious traditions, the Flood was one that could be expected to have left substantial physical traces. As a precious human record from the distant past, the story would have been used as an explanatory resource for understanding the natural world, even if it had not been privileged still more as a part of sacred scripture.

By being a putatively historical event, the Flood story belonged both to the world of religious meaning - at least for historical religions such as Judaism and Christianity - and to the world of physical explanation. Consequently, its role in the complex interaction between religious and scientific understanding has been quite different from that of, say, 'arguments from design'; for these, in forms both ancient and modern, are intrinsically ahistorical.

Norman Cohn, the author of The Pursuit of the Millennium (1957) and other important historical works, has now written an attractive brief survey of the fortunes and uses of the Flood story, ranging from ancient Mesopotamia to the equally alien territory of twentieth-century American creationism. On the way, he takes in the period of intense physical theorizing about the Earth in the seventeenth century, which

\title{
Diving to the depths in pursuit of history
}

Underwater exploration has a long history, as Jean-Yves Blot shows in his new book. He writes: "In 1446 the Italian architect and writer Leon Battista Alberti searched Lake Nemi near Rome for traces of two great Roman vessels whose existence had long been part of local folklore, fuelled by the sporadic finds of fishermen." Alberti found pieces of wood from the wrecks which he thought dated from the era of the Emperor Trajan, who died in $117 \mathrm{AD}$. Blot brings the story up to date by describing the dangerous and exciting work of modern divers. The wreck of the Byzantine vessel Yassi Ada I, discovered at a depth of 36 metres in the Mediterranean, was found to hold a cargo of 900 amphorae (right).

Underwater Archaeology: Exploring the World Beneath the Sea is one of the latest titles in the excellent series of New Horizons paperbacks from Thames and Hudson (£6.95).

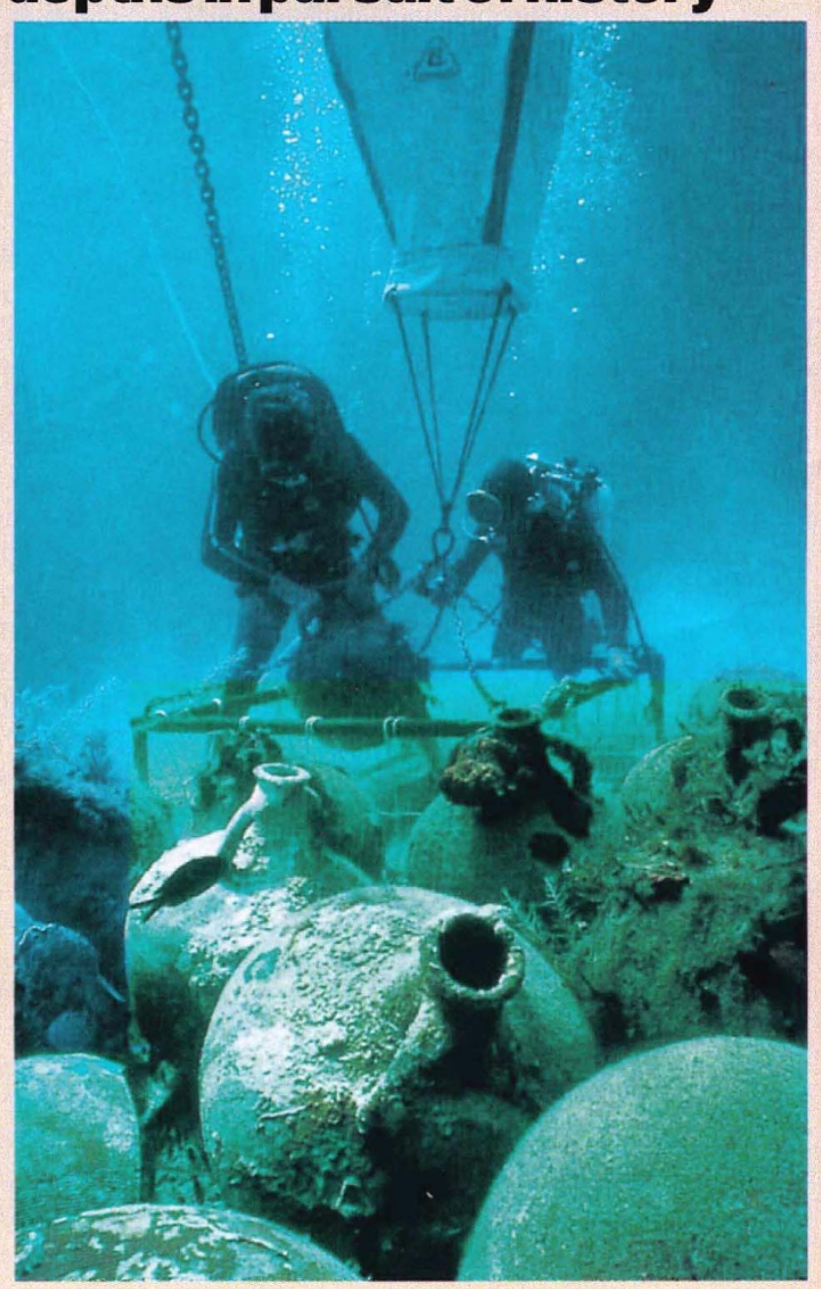

